\title{
Study on Measurement of Dynamic Stress Induced by Nd:YAG Laser Beam
}

\author{
T. FURUMOTO ${ }^{* 1}$, T. UEDA ${ }^{* 1}$, S. AOKI ${ }^{* 2}$, A. KASAI $^{* 2}$, \\ A. HOSOKAWA ${ }^{* 1}$, R. TANAKA ${ }^{* 1}$ and H. TACHIYA ${ }^{* 1}$ \\ ${ }^{* 1}$ Institute of Science and Engineering, Kanazawa University, \\ Kakuma-machi, Kanazawa, Ishikawa 920-1192, Japan \\ E-mail: furumoto@t.kanazawa-u.ac.jp \\ ${ }^{* 2}$ Graduate School of Natural Science and Technology, Kanazawa University, \\ Kakuma-machi, Kanazawa, Ishikawa 920-1192, Japan
}

\begin{abstract}
In dental treatment, a laser beam has been used for various surgical treatments of hard and soft tissues. Recently, there has been considerable interest in the bactericidal effect induced by laser beam irradiation. This paper deals with the measurement of dynamic stress induced in extracted human enamel by irradiation with Nd:YAG laser beam. The laser beam can be delivered to the specimen through a quartz optical fiber. The dynamic load induced in the specimen by using elastic wave propagation in the cylindrical long bar made of aluminum alloy was measured. The human enamel was grinded with the grain size of $26 \mu \mathrm{m}$, and carbon powder and titanium dioxide powder were applied to the surface so as to absorb the laser beam effectively. The laser induced stress intensity was evaluated from the dynamic strain measured by small semiconductor strain gauges. The result showed that the induced dynamic stress increased with the increase of laser energy in each absorbent. The induced dynamic stresses with $\mathrm{TiO}_{2}$ powder were superior to that with carbon powder. The induced dynamic stress was related to the volume of prepared cavity. The induced stress for the removal of the unit volume of human enamel was $0.03 \mathrm{~Pa} / \mathrm{mm}^{3}$.
\end{abstract}

DOI: $10.2961 / \mathrm{j} l \mathrm{mn} .2010 .01 .0013$

Keywords: dental treatment, Nd:YAG laser beam, bactericidal effect, dynamic stress, long bar, human enamel, carbon powder, titanium dioxide powder, dynamic load measurement, eliminated volume

\section{Introduction}

A laser beam has several unique properties that make it useful for a variety of applications in dental treatment, such as not only a substitute of a rotary cutting instrument but also the increment of an acid resistance of enamel and the scalpel for soft tissues [1,2]. Recently, there has been considerable interest in bactericidal effect induced by a laser beam irradiation. Many types of laser beams, such as $\mathrm{Nd}$ :YAG laser [3,4], Er:YAG laser [5] and semiconductor laser [6], have been investigated about the bactericidal effects. Sterilization of bacteria might be caused by the thermal, chemical and mechanical effects induced by a laser beam irradiation [5]. However, most of the work has been performed by irradiating to the agar plate with bacteria, and very few studies have been reported on the physical mechanism of the bactericidal effects.

When the laser beam is irradiated to the specimen, the laser induced stress intensity is generated around the laser beam irradiated area. Many papers had been reported about the measurement of the laser induced stress intensity with piezo-electric element and pressure gauge[7,8]. The final goal of our study is to solve the mechanism of bactericidal effects induced by a laser irradiation. This paper deals with the measurement of a dynamic stress induced by a $\mathrm{Nd}$ :YAG laser beam irradiation on the extracted human enamel. The dynamic load induced in the specimen by using elastic wave propagation in the cylindrical long bar made of aluminum alloy is measured. The intensity of the laser induced stress is evaluated from the dynamic strain measured by small semiconductor strain gauges. From the results, the influences of the irradiation and absorbents of the laser on the surface of human enamel are experimentally clarified.

\section{Theory of elastic wave propagation in long bar}

The schematic illustration of elastic wave propagation in a cylindrical long bar is shown in Fig. 1. It is assumed that a length of the long bar is large enough compared with a diameter of the long bar and the other end of the long bar is free. When a dynamic force $\sigma(\mathrm{t})$ is loaded at the end of

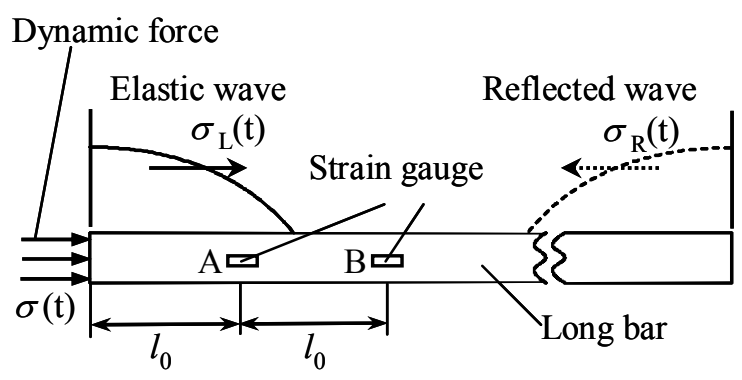

Fig. 1 Schematic illustration of elastic wave propagation in cylindrical rod 
the long bar, an induced elastic wave travels without the change in form so long as the diameter of the long bar is small compared with the length of the pulse [9]. Additionally, when the length of the long bar is semi-infinite, the dynamic force at the point $\mathrm{A}$ after time $t_{0}$ is expressed as following formula $[10,11]$.

$$
\sigma(\mathrm{t})=\sigma_{\mathrm{A}}\left(\mathrm{t}+t_{0}\right)
$$

The velocity of the elastic wave propagation is dependent on the bar material, and is given as follows.

$$
C_{0}=\sqrt{\frac{E}{\rho}}
$$

where $E$ is Young's modulus and $\rho$ is density of the long bar. Thus, time $t_{0}$ in formula (1) is leaded as follows.

$$
t_{0}=\frac{l_{0}}{C_{0}}
$$

where $l_{0}$ is the distance from the end of the long bar to point A. From equation (1) to (3), the waveform at the point $\mathrm{A}$ is obtained by transferring the waveform at the end of long bar for the time interval $t_{0}$.

When the traveled elastic pulse wave reaches to the other end of the long bar, the sign of the pulse wave is changed, that is, the tension pulse whose absolute value is the same as the incident compression pulse [9]. Therefore, the added stress at the end of the long bar is expressed as follows [10].

$$
\sigma(\mathrm{t})=\sigma_{\mathrm{L}}(\mathrm{t})+\sigma_{\mathrm{R}}(\mathrm{t})
$$

where $\sigma_{\mathrm{L}}(\mathrm{t})$ is compression pulse wave traveled to the right side and $\sigma_{\mathrm{R}}(\mathrm{t})$ is tension pulse wave traveled to the left side. When the distance from the point $\mathrm{A}$ to the point $\mathrm{B}$ is same as $l_{0}$, the dynamic force $\sigma_{\mathrm{A}}(\mathrm{t})$ at the point $\mathrm{A}$ and $\sigma_{\mathrm{B}}(\mathrm{t})$ at the point $\mathrm{B}$ is given as the follows, respectively [10].

$$
\begin{aligned}
& \sigma_{\mathrm{A}}(\mathrm{t})=\sigma_{\mathrm{L}}\left(\mathrm{t}-t_{0}\right)+\sigma_{\mathrm{R}}\left(\mathrm{t}+t_{0}\right) \\
& \sigma_{\mathrm{B}}(\mathrm{t})=\sigma_{\mathrm{L}}\left(\mathrm{t}-2 t_{0}\right)+\sigma_{\mathrm{R}}\left(\mathrm{t}+2 t_{0}\right)
\end{aligned}
$$

From (1) to (5), the dynamic force loaded at the end of the long bar is calculated as follows [10].

$$
\sigma(\mathrm{t})=\sigma_{\mathrm{A}}\left(\mathrm{t}+t_{0}\right)+\sigma_{\mathrm{A}}\left(\mathrm{t}-t_{0}\right)-\sigma_{\mathrm{B}}(\mathrm{t})
$$

Therefore, the dynamic force loaded at the end of the long bar can be determined from the measurement of the dynamic forces at both the point $\mathrm{A}$ and the point $\mathrm{B}$.

\section{Experimental set up and conditions \\ 3.1 Laser facility}

In this study, a pulsed Nd:YAG laser facility (Altech co., ltd.: STREAK I), which is mainly used for dental treatment, has been used. The specifications of this facility are given in Table 1. The wavelength is $\lambda=1064 \mathrm{~nm}$. The irradiation energy per pulse and the pulse duration can be changed precisely. A laser beam is transmitted through a quartz optical fiber with a core diameter of $400 \mu \mathrm{m}$. A numerical aperture of this optical fiber is $N A=0.37$, therefore, the beam divergence angle is about $22^{\circ}$.
Table 1 Specifications of the laser facility

\begin{tabular}{lcl}
\hline Laser & & Nd:YAG $(\mathrm{PW})$ \\
Wavelength & $\lambda$ & $1064 \mathrm{~nm}$ \\
Peak power & $P$ & $1-4 \mathrm{~kW}$ \\
Irradiation energy & $E_{1}$ & $50-990 \mathrm{~mJ} /$ pulse \\
Pulse duration & $\tau$ & $50,100,200$ and $400 \mu \mathrm{s}$ \\
Frequency & $f$ & $1-99 \mathrm{~Hz}$ \\
\hline Optical fiber & & Quartz \\
Core diameter & $\phi_{c}$ & $400 \mu \mathrm{m}$ \\
Numerical aperture $N A$ & 0.37 \\
\hline
\end{tabular}

\subsection{Measurement of eliminated volume on enamel}

In order to investigate the influence of laser irradiation conditions on the eliminated volume, a cavity was prepared on the extracted human enamel surface. The irradiated laser energy to the enamel surface ranged from 50 to $990 \mathrm{~mJ}$ per pulse. The enamel surface was grinded with the grain size of $26 \mu \mathrm{m}$ as the surface and bottom of the grinded specimen were parallel. Carbon powder (SLT-Japan Co., Ltd.: MK 2404) and titanium dioxide powder (Miyako Chemical Co., Ltd.: Avant tooth liquid XBS) were applied to the human enamel surface so as to absorb the irradiated laser beam effectively. The thickness of the absorbent on the surface was thin enough compared with that of the human enamel. The fiber tip was contacted to the human enamel surface during the laser irradiation, and a single pulse laser beam was irradiated to the surface. The spot size of the irradiated laser beam at the enamel surface was $400 \mu \mathrm{m}$. The prepared cavity was measured with 3-dimmensional surface profiling system (Tokyo Seimitsu Co., Ltd.: SURFCOM) after the absorbent on the surface was eliminated.

\subsection{Measurement of induced dynamic stress}

A procedure for the measurement of a dynamic stress induced by a laser beam irradiation is schematically illustrated in Fig. 2, and the experimental conditions are given in Table 2. The procedure uses a cylindrical long bar and strain gauges. The frequency response of the strain gauge which was attached on the long bar was $300 \mathrm{kHz}$ and its operating temperature range was from -50 to $150{ }^{\circ} \mathrm{C}$. This system can measure a dynamic load induced in the specimen by using elastic wave propagation in the long bar. The long bar was a diameter of $\phi=10 \mathrm{~mm}$ and a length of $L$ $=2000 \mathrm{~mm}$. The long bar made of aluminium alloy (JIS: A5052) was applied to cancel the influence of magnetostriction. The strain gauge used was small semiconductor strain gauges (Kyowa Electronic Instruments Co., Ltd.: KSP-1-350-E4) which has high responsibility and can measure slight strain. The strain gauge was attached at the position of $200 \mathrm{~mm}$ and $400 \mathrm{~mm}$ from the end of the long bar, respectively. In each position, the strain gauge was symmetrically attached with respect to the long bar to restrain the influence of bending stress induced in the long bar. The specimen used was extracted human enamel and its surface was grinded with the grain size of $26 \mu \mathrm{m}$ as the 
Table 2 Experimental conditions

\begin{tabular}{lcc}
\hline Strain gauge & & KSP-1-350-E4 \\
Gauge length & $L_{\mathrm{gs}}$ & $1 \mathrm{~mm}$ \\
Resistance & $R_{\mathrm{gs}}$ & $350 \mathrm{~W}$ \\
\hline Amplifier & & CDV-700A \\
Frequency response & DC - 500 kHz \\
\hline Bar & \\
Material & & Alminium alloy \\
& & (JIS A5052) \\
Length & $L$ & $2000 \mathrm{~mm}$ \\
Diameter & $\phi$ & $10 \mathrm{~mm}$ \\
\hline
\end{tabular}

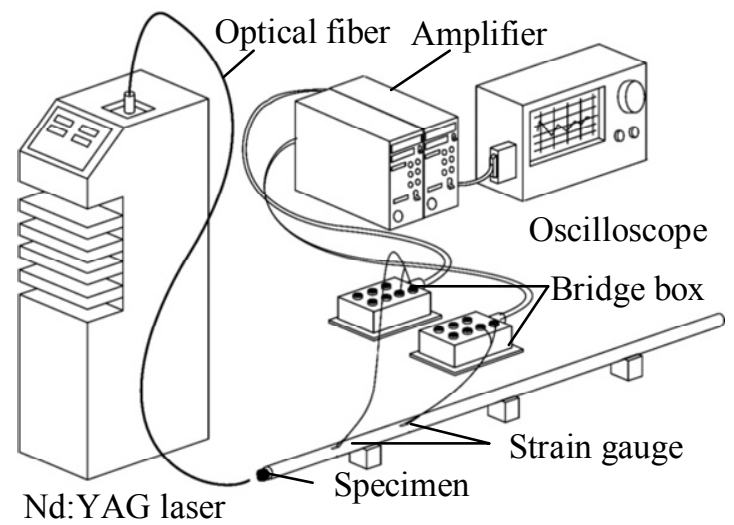

(a) Overall view

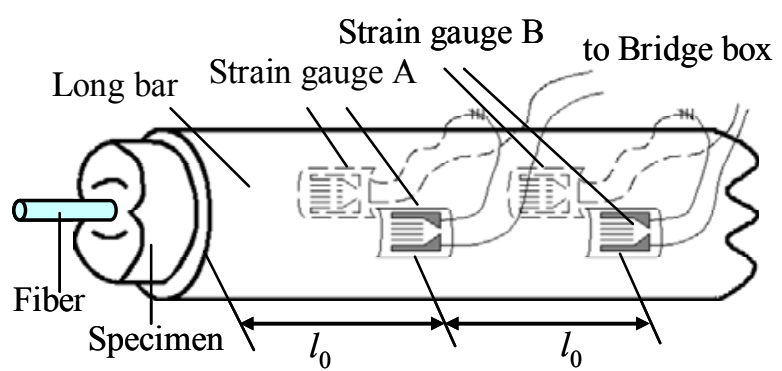

(b) Enlargement of bar tip

Fig. 2 Experimental set up for measurement of induced dynamic stress

surface and bottom of the grinded specimen were parallel. The specimen was set with a glue on the end of the long bar, and carbon powder and titanium dioxide powder was applied to the human enamel surface. The fiber tip was contacted to the enamel surface during the laser irradiation. The laser-induced stress intensity was evaluated from the dynamic strain measured by the strain gauges. The thickness of the specimen was thin enough compared with the length of the long bar. Therefore, it was assumed that the induced stress distribution in the human tooth was uniform, and the dynamic stresses induced at the end of the long bar was same as that at the surface applied to the absorbent.

\section{Results and discussions}

\subsection{Cavity preparation on human enamel}

The 3-D image of the prepared cavity on the human enamel is illustrated in Fig. 3, and SEM image (JEOL Ltd.:

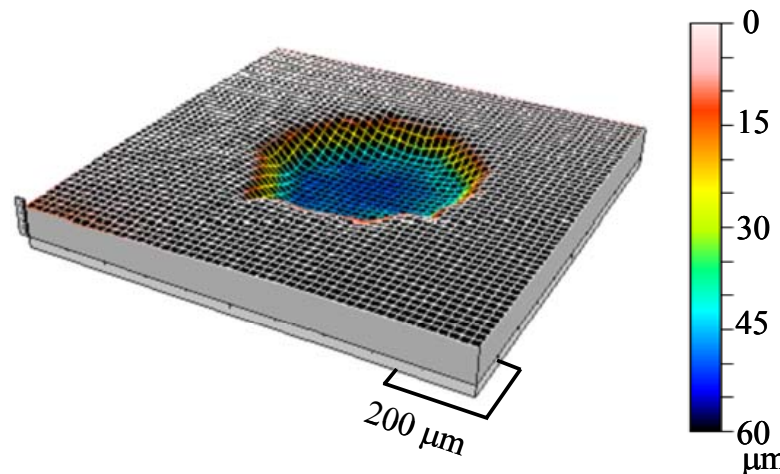

Fig. 3 3D images of prepared cavity with $\mathrm{TiO}_{2}$ powder $\left(E_{1}=600 \mathrm{~mJ} /\right.$ pulse, $\left.\tau=400 \mu \mathrm{s}\right)$

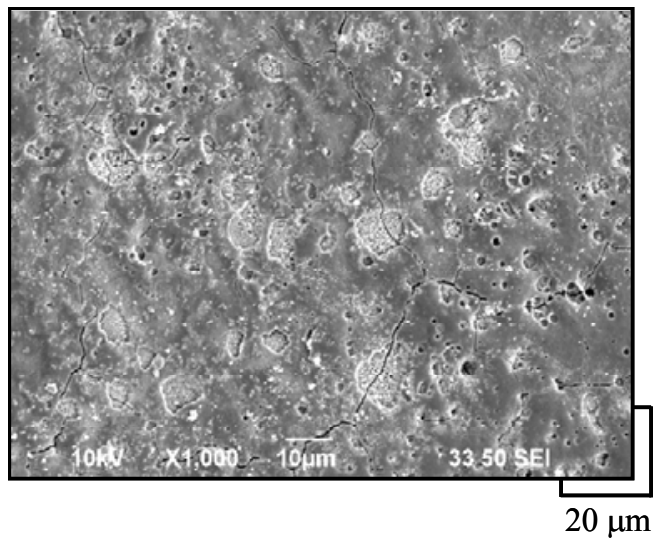

Fig. 4 SEM image of cavity surface

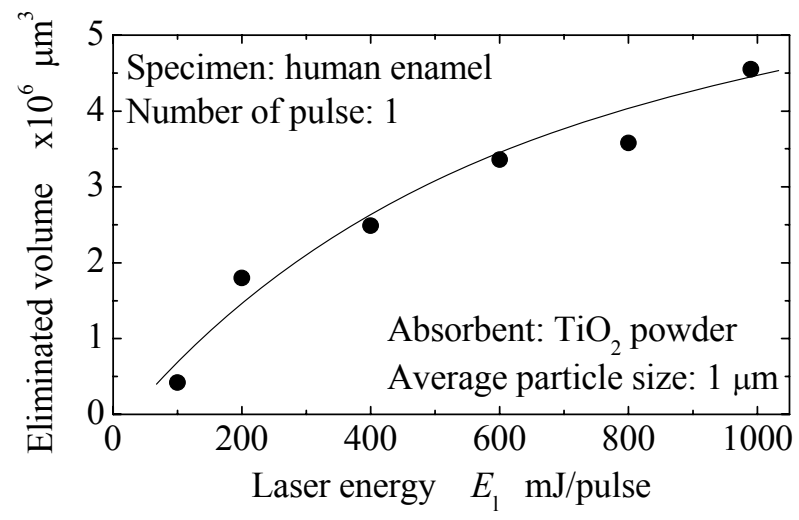

Fig. 5 Variation of cavity volume with laser energy

VSM-6290LVU) of the cavity surface is shown in Fig. 4. The titanium dioxide powder was applied to the enamel surface as the absorbent. As were obvious from the 3-D image, the cavity was formed corresponding to the laser beam irradiation. The diameter of the cavity was almost same as the core diameter of the optical fiber, and the maximum depth of the cavity was $49 \mu \mathrm{m}$. In addition, there was the heat affected zone on the enamel surface, as shown in Fig. 4. These results showed that the enamel surface was fused and evaporated by the laser beam irradiation and resulted in the preparation of cavity.

The variation of the eliminated volume at human enamel surface with the laser energy is shown in Fig. 5. 
The eliminated volume increased with the increase of the laser energy. When the laser energy was $E_{1}=600 \mathrm{~mJ} / \mathrm{pluse}$, which was generally used in dentistry clinical, the eliminated volume at the human enamel surface was $3.4 \times 10^{6}$ $\mu \mathrm{m}^{3}$. It was clear that the preparation of the cavity was influenced with the laser energy.

\subsection{Output wave from long bar}

Figure 6 shows the typical output profiles from the strain gauges attached on the cylindrical long bar. The strain $\varepsilon_{\mathrm{A}}$ represents the output voltage with the position of $200 \mathrm{~mm}$ and the strain $\varepsilon_{\mathrm{B}}$ represents with the position of $400 \mathrm{~mm}$, respectively. When the elastic wave passed through the position on which the strain gauge was attached, the output signals were immediately detected by each detector and converted into the electric signal. The output signals at the strain $\varepsilon_{\mathrm{A}}$ reached the maximum value when $730 \mu \mathrm{s}$ had passed from the detection of the elastic wave, and then decreased. The decrease of output signals showed that the reflected elastic wave reached the position

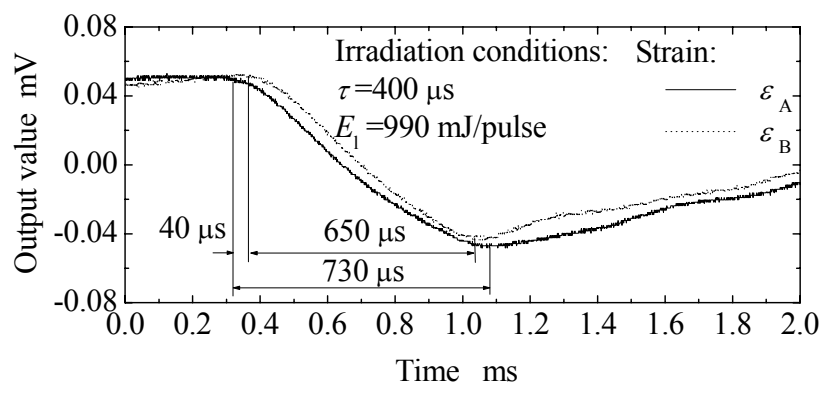

Fig. 6 Output wave of strain gauge

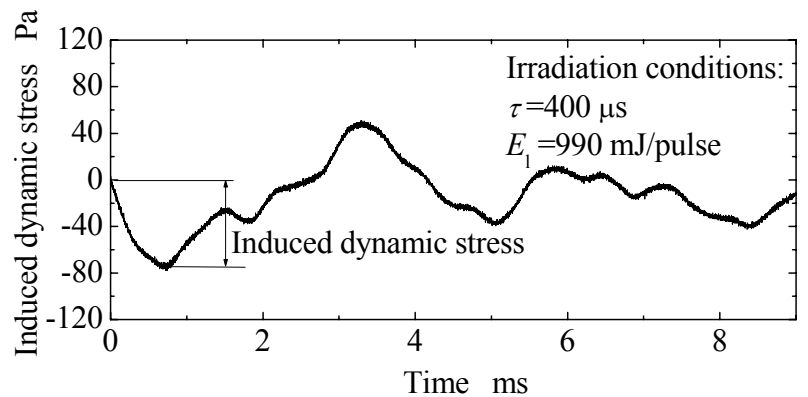

Fig. 7 Calculated stress at bar edge

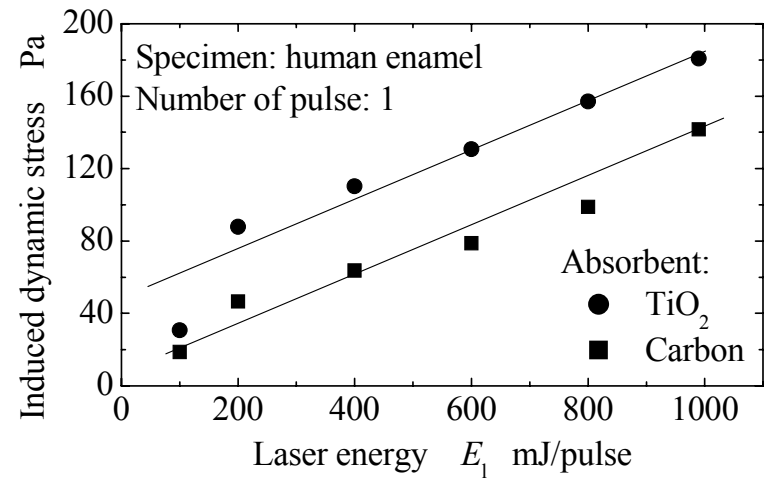

Fig. 8 Influence of laser energy on dynamic stress on which the strain gauge was attached. The output signals at the strain $\varepsilon_{\mathrm{B}}$ reached the maximum value when $670 \mu \mathrm{s}$ had passed. The velocity of the elastic wave propagation in the aluminum alloy is $5004 \mathrm{~mm} / \mathrm{s}$. Therefore, the time interval coincided well with the velocity of the elastic wave propagated in the long bar.

Figure 7 shows the elastic wave loaded at the end of the long bar which is calculated by formula (6). As was obvious from the graph, the calculated elastic wave varied periodically, and decreased gradually. Hence, the variation of the induced dynamic stress at the end of the long bar was evaluated with the maximum amplitude of the calculated elastic wave.

\subsection{Effect of the absorbent on induced dynamic stress}

The variation of induced dynamic stress with laser energy is shown in Fig. 8. The induced dynamic stress increased with the increase of laser energy in each absorbent. The induced dynamic stresses with $\mathrm{TiO}_{2}$ powder were superior to that with carbon powder. When the laser energy was $E_{1}=600 \mathrm{~mJ} /$ pluse, the induced dynamic stress was $\sigma=130 \mathrm{~Pa}$ in $\mathrm{TiO}_{2}$ powder and $\sigma=80 \mathrm{~Pa}$ in carbon powder. These differences could be explained on the basis of the physical properties of the absorbents. The physical properties of the absorbent applied to the human enamel surface are given in Table 3 [12]. The thermal conductivity and heat capacity of the titanium dioxide powder were quite small compared with that of carbon powder. In contrast, density of titanium dioxide powder was almost twice compared with that of carbon powder. Therefore, the heating of titanium dioxide powder was superior to carbon powder, and resulted in the difference of the induced dynamic stress.

Figure 9 shows the variation of the induced dynamic

Table 3 Physical properties of absorbent

\begin{tabular}{lc|c|c}
\hline & & $\mathrm{TiO}_{2}$ & $\mathrm{C}$ \\
\hline Density & $\mathrm{kg} / \mathrm{m}^{3}$ & 4240 & 2267 \\
Melting point & $\mathrm{K}$ & 2143 & \\
Boiling point & $\mathrm{K}$ & 3200 & 3643 \\
Thermal conductivity & $\mathrm{W} / \mathrm{m} \cdot \mathrm{K}$ & 7 & $80-230$ \\
Heat capacity & $\mathrm{J} / \mathrm{mol} \cdot \mathrm{K}$ & 55 & 710 \\
\hline
\end{tabular}

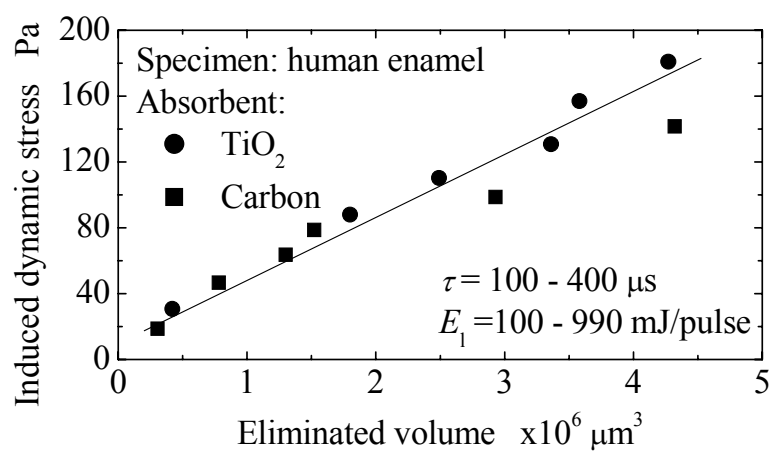

Fig. 9 Influence of prepared cavity on dynamic stress 
stress on the human enamel surface with the eliminated volume in each absorbent. As was obvious from the graph, the induced dynamic stress increased proportionately with the increase of the eliminated volume. In addition, there was no influence of the absorbent to the eliminated volume. The induced dynamic stress when the unit volume on the human enamel surface was eliminated was $0.03 \mathrm{~Pa} / \mathrm{mm}^{3}$. It was clear that the induced dynamic stress was related to the eliminated volume on the human enamel surface.

\section{Conclusions}

The dynamic stress induced in extracted human enamel, by irradiation with a Nd:YAG laser beam, was measured according to the theory of elastic wave propagation in a cylindrical long bar. The influence of the laser beam conditions and absorbents applied to the human enamel surface on the induced dynamic stress was investigated. The results obtained were follows.

(1) The eliminated volume on the extracted human enamel surface increased with the increase of laser energy, and there was the heat affected zone on the surface.

(2) The dynamic stress induced by the laser beam irradiation increased with the increase of laser energy.

(3) The induced dynamic stresses with $\mathrm{TiO}_{2}$ powder were superior to that with carbon powder.

(4) The induced dynamic stress when the unit volume on the human enamel surface was eliminated was 0.03 $\mathrm{Pa} / \mathrm{mm}^{3}$.

\section{Acknowledge}

The authors would like to thank to Dr. Sugihara and Dr. Waga for the precious advice about dentistry. The dental treatment device used in this research is supported by Altech Co., ltd, and this research was financially supported from Grant-in-Aid for Young Scientists (B) (No. 19791395).

\section{References}

[1] M. Kumazaki, H. Fujiwara, H. Matsuda, K. Zennyu, M. Kumazaki, K. Toyoda and B. Fujii: Excision of Dental Caries, J. Jpn. Soc. Laser Dent., 3, (1992) 19-22. (Journals) (in Japanese)
[2] K. Suzuki, E. Morita and T. Morioka: An Increment of Acid-resistance of Dental Enamel with the Irradiation of Various Types of Laser Beam (2nd Report), , J. Jpn. Soc. Laser Surg. And Med., 3, 1, (1982) 613-618 (Journals) (in Japanese)

[3] A. Grönqvist, J. Wiström, O. Axner and T.J. Monsen: Bactericidal effect of pulsed 1064nm Nd:YAG laser light on staphylococcus epidermidis is of photothermal origin, An in vitro study, Lasers Surg. Med., 27, 4, (2000) 336-340. (Journal)

[4] G. Meral, F. Tasar, S. Kocagöz and C. Sener: Factors affecting the antibacterial effects of Nd:YAG laser in vivo, Lasers Surg. Med., 32, 3, (2003) 197-202. (Journal)

[5] M. Türkün, L.S. Türkün, E.U. Celik and M. Ates: Bactericidal effect of Er, Cr:YSSG laser on streptococcus mutans, Dent. Mater. J., 25, 1, (2006) 81-86. (Journal)

[6] B.S. Lee, Y.W. Lin, J.S. Chia, T.T. Hsieh, M.H. Chen, C.P. Lin and W.H. Lan: Bactericidal effects of diode laser on streptococcus mutans after irradiation through different thickness of dentin, Lasers Surg. Med., 38, 1, (2006) 62-69. (Journal)

[7] C.M. Percival: Laser-generated stress waves in a dispersive elastic rod, Journal of Applied Physics, 38, 13 (1967) 5313-5315. (Journal)

[8] N.C. Anderholm: Laser-generated stress waves, Applied Physics Letters, 16 (1970) 113-115. (Journal)

[9] H. Kolsky: "Stress waves in solids" (Dover Pubns, USA, 1963) p.89. (Books)

[10] N. Yanagihara: The measuring method of impact force by the theory of propagation of longitudinal elastic stress wave, Transactions of the Japan Society of Mechanical Engineers, 43, 375, (1977) 4048-4052. (Journals) (in Japanese)

[11] B. Lundberg and A. Henchoz: Analysis of elastic waves from two-point strain measurement, Experimental Mechanics, 17, 6, (1977) 213-218.

[12]Г. В. САМСОНОВА, Физико-химическиеСвойства Окислов, Москва “Металлургия", Moscow, 1978. (books).

(Received: June 12, 2009, Accepted: January 18, 2010) 